\title{
DEMOCRACY SATISFACTION THROUGH THE MEDIATING EFFECTS OF ELECTION CAMPAIGNS
}

\author{
Dilan ÇİFTÇİ \\ Near East University, Faculty of Communication \\ dilan.ciftci@neu.edu.tr
}

\begin{abstract}
In this research the role of democracy satisfaction was tested on the interest in election campaigns change and the mediating role that political interest plays in this relation. By conducting single and multiple regressions, the presented conceptual model seemed to be valid. Because two affects that were expected to be significant positive and the results show positive relationship between democracy satisfaction and interest in politics, and between political interest and interest in election campaigns.
\end{abstract}

Keywords: democracy satisfaction, election campaigns, political interest, political engagement

\section{SEÇIM KAMPANYALARININ ARACILI ETKISİ VE DEMOKRASI MEMNUNIYETI}

\section{$\ddot{O Z Z}$}

$\mathrm{Bu}$ araştırmada, demokrasi memnuniyeti bağlamında seçim kampanyalarındaki değişiklik ve seçim ile doğrudan ya da dolaylı ilişkisi test edilmiştir. Tekli ve çoklu regresyon yapılarak, sunulan kavramsal modelin geçerliliği tartışılmıştır. Sonuçların anlamlı ve pozitif olması beklenmektedir. $\mathrm{Bu}$ sayede demokrasi memnuniyetinin siyasi ilgi ve seçim kampanyaları ile anlamlı bir ilişkisi olduğu öne sürülmüştür.

Anahtar kelimeler: demokrasi paylaşım, seçim kampanyaları, politik tercihler

\section{Introduction}

The election periods are always seen as the horse races. Therefore, the well-formed campaign strategies are necessary in order to keep election turnout high. During the European Parliamentary election and referendum campaigns, the overall news environment put more emphasis on potential advantages of a common EU unifications rather than on possible negative consequences (Schuck \& de Vreese, 2009, 47-50). Election campaigning is one of the things that characterizes today's political communication. Almost each party and organization feels the need for campaigning to increase their voters' rates, but also to keep their voters for competing with other parties, candidates and organizations. The general assumption is that people who interested with politics are most likely attending election campaign activities. On the other hand, the direct personal campaign engagement affect turnout positively, but not necessarily give direction to the vote choice.

The results showed that campaigns in consensual electoral contexts in which political parties differ marginally on most issues of European integration were longer and involved more public meetings, more canvassing, and a more active use of Internet. The article concludes with a discussion of the campaign professionalization literature that does not apply universally. On the other hand, it is important how citizen satisfied with the way democracy works in the European Union. Therefore, the way democracy works in the European Union might affect the interest in election campaign activities such as; watching a program about the election on TV, reading about the election in a newspaper, talk to friends or family about the election and looked into website concerned with the election.

\section{Theoretical Background}


To begin with the Blumler \& Kavanagh (1999) there are three major age of political communication that should be separately observed in terms of influences and features. Clearly, Blumler \& Kavanagh (1999) said that the notion of political communication has changed with regards of the effects of postwar period. Therefore, most scholars would agree on the idea that not only important changes in the society, but also new trends in media would serve the new form of political communication that is directly different from the earliest model. Significantly, according to Blumler \& Kavanagh (1999), new trends in media have also big impact on the transformation of the political journalism that serves the new rooms for debate of democracy and citizenship. (Blumler \& Kavanagh: 1999; 209).

Moreover, as Blumler \& Kavanagh (1999) mentioned that new trends are the results of the social change to media that brought about the 7 chain of exogenous change which are modernization, individualization, secularization, economization, anesthetization, rationalization, mediatization. First, modernization is vital change in order to make minority media more apparent and viable. Second, individualization provides the idea that citizens are more like consumers. Thus, politicians should put more emphasis on their work to retain their support and interest. Third, political authorities lose their power by exercising the media and political pluralism. Moreover, both economization and aestheticization is about the autonomous spheres and popular culture, which are encourages criteria of economic factors and values on the political agenda. On the other hand, rationalization promotes the sustain policy debates. Lastly, mediatization favors the concept of a "media-constructed public sphere" (Blumler \& Kavanagh: 1999; 210-211).

Significantly, Blumler \& Kavanagh (1999) explained the three different ages of communication system. The Age 1 is referring to substantive political messages, enjoyable access to mass media and the selectivity and reinforcement of respondents'. Gradually, in age 2 political communications has faced with the change in medium of even-handed news to television, which takes a part in enlargement of the audience for political communication. According to Blumler \& Kavanagh (1999) with the help of the Age 2, citizens are tended to be more open-minded and flexible for different approaches. Finally, in Age 3 emerging the main means of communication adapt with the professionalization and commercialization. Meanwhile, it is true to say that with the more fragmented communication system providing the response to daily events will be more indispensable (Blumler \& Kavanagh: 1999; 211 215).

Similar with the Blumler \& Kavanagh (1999), Brants \& Praag (2006) emphasized the importance of the transmission between the ages of the political communication by saying that we are all witnessing the further meaning of communication professionalization. In addition, Brants \& Praag (2006) introduced the different media systems, which are liberal, polarized pluralist, democratic corporatist model. Respectively, Brants \& Praag (2006) support that US and UK media systems fit with the liberal model, which is characterized by neutral commercial press. In addition to that, UK broadcasting system enjoys with its autonomous system. Although there are possible differences between each models, Brants \& Praag (2006) mostly focused on the 'democratic corporatist' model that is applied in Netherlands. Clearly, in Netherlands media system has consensual politics which means, while involvement of the state in the welfare economy is included, there are still high political parallelism exist in the system (Brants \& Praag: 2006; 25-27).

Furthermore, Brants and Praag (2006) clarified the distinction between the partisan logic and media logic. In the light of this explanation, Brants \& Praag (2006) defined the partisan logic by using the 'platform' metaphor in order to say that in the nineteenth and early twentieth century, most press and broadcasting were used to emancipation and socialization of the electorate. As in this model, independent journalism did not exist, journalist in partisan logic would be considered as lap dogs instead of watchdogs. Especially, as Brants and Praag (2006) explained that in the 1960s, Netherlands political communication was driven by the media logic rather than a partisan logic. Therefore, as Brants \& Praag (2006) dealt with, with the rise of the media logic, political communication was emancipated from the ideological and religious ties, which are the direct results of the existence of “de-confessionalised and de-ideologised" electorate (Brants \& Praag: 2006;28-30). 
Specifically, Brants \& Praag (2006) searched on the media logic in the Netherlands by focusing on the 1956, 1986 elections and 2003 campaign. Respectively, while 1956's election would be the good example of partisan logic as none of the media took part in setting the campaign agenda, in 1986's election Netherlands experienced with the new term of 'public logic' by the process of de-pillarization. Essentially, this process brought about the substantive coverage to campaign with the results of the increasing citizen-oriented TV-journalists. Consequently, in 2003 campaign, there was a sharp decrease in the number of national and regional newspapers with regards of the argument that culturally Netherlands faced with the 'de-reading' process. Finally, as Brants \& Praag (2006) emphasized in their article, there is a apparent transmission from the partisan logic to public logic and media logic, which refers to clear changes in the media landscape (Brants \& Praag: 2006; 31-37).

Compare with the below authors, Aelst, Brants \& Praag, et al. (2008) concentrated on the perceptions of media power. Initially, most of the media scholars are agreed on that media has undeniable effects on political arena over the 20 years, whereas some support the charge of parties and politicians. Aelst, Brants \& Praag, et al. (2008) articulated the shortcomings of the power of media in two main points. First, political opinion, attitudes or behavior would be influenced by media power. Besides, although power of the media is often over the public, it is not necessary case that power over politics should exist. Nevertheless, they also suggest that power of the media could possibly change with different political structure. Second, power of the media over political agenda did not properly mentioned in early studies of media studies, which considered as power of the media over politics relegated to the periphery (Aelst, Brants \& Praag, et al. : 2008; 494-496).

Furthermore, Aelst, Brants \& Praag, et al. (2008) classified two different approaches to the concept of power, which are actor oriented and structural approach. To begin with the actor-oriented approach, it is clear to say that actor-oriented power of media refers to allowing one to use their power in order to organize and mobilize. On the other hand, consequence of the social relations that affect people is related with the structural approach, which seems power as a system property. In spite of this classification, as Aelst, Brants \& Praag, et al. (2008) pointed out that the process of political communication provides three different actor groups, which are news producers, politicians and the public. Significantly, Althusser's concept of ideological state apparatuses would fit the structural approach to media power relationships (Aelst, Brants \& Praag, et al.:2008; 495-498).

As Aelst, Brants \& Praag, et al. (2008) argued that while comparing the past, over the last decade, there is an increasing role of media power in political life. Interestingly, Aelst, Brants \& Praag, et al. (2008) come up with the conclusion that culture could not effectively changed the power of media use in political system. To illustrate this, Aelst, Brants \& Praag, et al. (2008) indicated although the Belgium and Netherlands has democratic corporatist model, they shared different views on media power relations with politics and politicians (Aelst, Brants \& Praag, et al.: 2008; 505-506).

Furthermore, Hallin and Mancini (2004) mostly focused on the homogenization and Americanization in studying media studies. Specifically, they pointed out that after World War 2 United States became the most influential country within the world's politics, economic, and cultural frame. On the other hand, the Cold War period is faced with the fascism that let most associations to think about "free press crusade". By defining some goals it is clear that American models of journalistic actions brought about the worldwide change in conceptualizing the journalism. Particularly, American design sensibility was affected the establishment of modernist form of local journalism as well as advertising (Hallin \& Mancini: 2004; 255-257).

In addition to that, Hallin and Mancini (2004) talked about the role of technology. Accordingly, it is true to say that the influences that made by technology upgrading has direct relationship with social context that mass communication adopted and implemented (Hallin \& Mancini: 2004; 260). Another significant point that Hallin and Mancini (2004) emphasized that is secularization, which refers to separations of citizen from attachments to religious and ideological "faiths". Typically, Hallin and Mancini used the "depillarization" of Dutch society, which can recreate the new varieties within the 
society. Finally, Hallin and Mancini (2004) focused on the commercialization that is about shifting from creating consensus to producing entertainment (Hallini \& Mancini: 2004; 277).

In this research therefore, the focus will be on the following research question:

How interest in an election campaign is influenced by democracy satisfaction and how is this mediated by political interest?

It is expected that satisfaction with democracy has a positive effect on interest in politics (H1). The more people are interested in politics, the more they will be interested in election campaigns, therefore, it is expected that interest in politics has a positive effect on interest in election campaigns (H2). The more people are satisfied with democracy on the other hand, will increase the interest they will have in election campaigns, therefore it is expected that satisfaction has a positive effect on interest in election campaigns. (H3). Consequently, it is expected that political interest has a mediated effect on interest in election campaigns (H4).

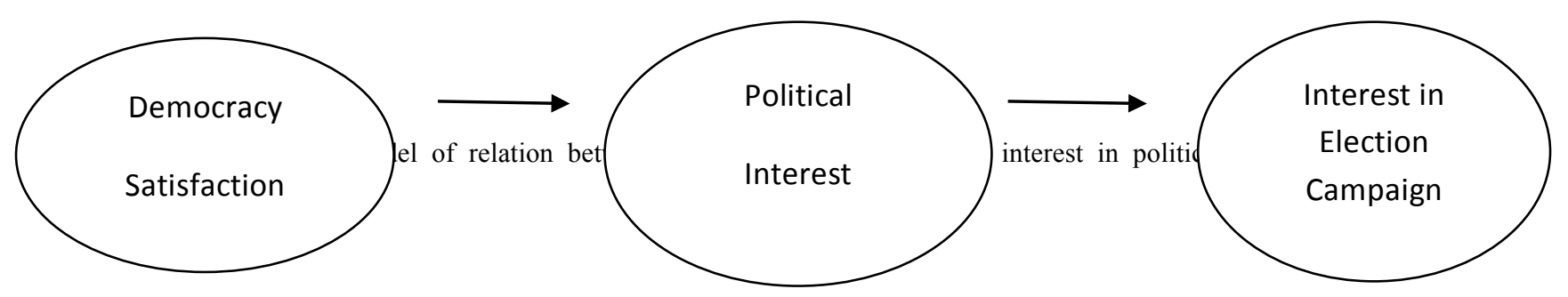

Selection and characteristics of research units

The analysis of this research is based on existing data from The Graduate School of Communication of the University of Amsterdam, led by van Egmond, Sapir, Van der Brug, Hobolt, and Franklin (2010). Data collection was done by CATI phone interview each EU member states. The target from each EU member states was 1,000 successful interviews. The study focuses on attitude and supports for European Parliamentary election and European unification amongst different EU member states. The questionnaire 2009 European Election Study 'Voter Study', was used which is based on the Master Questionnaire Template of van Egmond, Sapir, van der Brug, Hobolt, and Franklin (2010). The sample consisted of $44.1 \%$ females and $55.9 \%$ males. The mean age was $53(S D=5,4)$. The sample consisted of $40.8 \%$ employed, $6.8 \%$ unemployed and $29.8 \%$ retrieved people.

\section{Research Design \& Manipulated Variables}

The data file consists of three sets of variables, distinguished by the preceding characters $T, Q$ and $V$. T variables describe the interview [e.g., respondent id, country, date/length/mode of interview, et cetera.]. $Q$ variables comprise the interview questions. Both variable order and numbering reflect that of the 2009 questionnaire. V variables are additional variables, based either on additional information from the fieldwork agency, or derived on the basis of questionnaire variables. The first variable ('interest in election campaigns') in the questionnaire was measured on a four point scale ( $1=$ never, $4=$ often), and the second variable ('political interest') in the questionnaire was measured on a four point scale ( $1=$ not at all satisfied, $4=$ very satisfied), and the third variable ('democracy satisfaction') in the questionnaire was measured on a four point scale ( $1=$ not at all, $4=$ very).

- Interest in election Campaign: The dependent variable, namely interest in election campaigns, was initially constructed by computing 5 variables that measured different types of campaign activities. Five variables were re-coded. I have reversed the negatively worded items in the scale to calculate total scores. I was interested the valid cases, therefore $1.5 \%$ cases $[\mathrm{REF}=7, \mathrm{DK}=8]$ were excluded. Data were subsequently subjected to split-half reliability testing using Cronbach's Alpha on the five variables. The results show that collectively all the items reliably $(a=.62)$ construe interest in election campaign as a variable.

- Political Interest: The independent variable interest in politics was constructed by one continuous variable (item), therefore I do not need to do factor analysis and check reliability. I 
have reversed the responses for this item. I was interested with the valid cases, therefore $1.5 \%$ cases $[\mathrm{REF}=7, \mathrm{DK}=8]$ were excluded.

- Democracy Satisfaction: The independent variable democracy satisfaction was constructed by one continuous variable (item), therefore I do not need to do factor analysis and check reliability. I was interested with the valid cases, therefore $1.3 \%$ cases $[\mathrm{REF}=7, \mathrm{DK}=8]$ were excluded.

\begin{abstract}
Data Analysis
To test the hypotheses and consequently give an answer to the research question, the model has to be tested. To test the hypotheses, the three variables political interest, democracy satisfaction and interest in campaigns are tested. Because I want to test a causal relation, a single regression analysis for the first three hypotheses and a multiple regression analysis for the fourth hypothesis will be applied, based on the method of Baron and Kenny (1986). This analysis has four steps that are needed in order to test the mediating model. The first three steps are shown in figure 2. In every step (A, B, C) the correlation is measured of the two variables. If they seem to be correlating significantly, the fourth step can be taken; in step D the mediating effect can be measured to answer $\mathrm{H}$.
\end{abstract}

Figure 2: Three steps of Baron and Kenny (1986)

$\mathrm{C}$

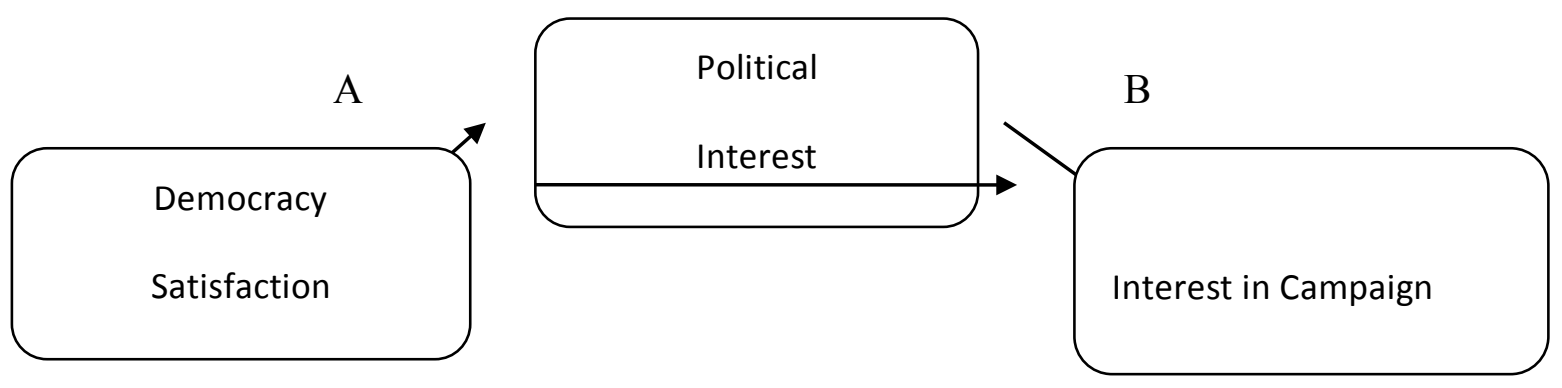

\title{
Findings
}

Step A. From the single regression with the constructed independent variable democracy satisfaction and the constructed dependent variable political interest there seemed to be a significant causal relationship $(F=358,91 ; d f=1 ; p<.001)$. Democracy satisfaction explains for $\% 14\left(R^{2}=.13\right)$ the variance in political interest. Democracy satisfaction shows to have a significant positive relationship with political interest $(B=.12 ; t=118,95 ; p<.001)$. If democracy satisfaction increases with 1 on the four point scale, political interest increases linear with 0,12 . H1 expected a positive effect of democracy satisfaction on political interest and because the effect shows to be positive, H1 can be adopted.

Step B. The second step following the method of Baron and Kenny (1986) consisted of the single regression of the mediating variable political interest on the dependent variable interest in election campaigns. There seemed to be a significant causal relationship $(F=81.34 ; d f=1 ; p<.001)$. Political interest explains for $\% 24\left(R^{2}=0,23\right)$ the variance in interest in election campaigns. Political interest shows to have a significant positive relationship with interest in election campaigns $(B=0,21 ; t=90,1$; $p<.001)$. If political interest increases with 1 on the four point scale, interest in election campaigns increases linear with 0,21 . H2 expected a positive relationship of interest in politics on interest in election campaigns and because the effect shows to be positive, $\mathrm{H} 2$ can be adopted.

Step C. Before the whole model could be tested, the single regression of the independent variable democracy satisfaction on the dependent variable interest in election campaigns had to be run. There seemed to be a significant causal relationship $(F=192,23 ; d f=1 ; p<.001)$. Democracy satisfaction explains for $\left(R^{2}=0,08\right)$ the variance in interest in election campaigns. Democracy satisfaction shows 
to have a significant positive relationship with interest in election campaigns $(B=0,40 ; t=13,8 ; p<$ .001). If democracy satisfaction increases with 1 on the four point scale, interest in election campaigns increases linear with 0,40. H3 expected democracy satisfaction to have a positive effect on interest in election campaigns, and because these expectations are confirmed by the results, $\mathrm{H} 3$ can be adopted.

Step D. For the last step the whole model is tested, with the mediating effect of political interest. Therefore a multiple regression is used. The results show a positive significant relation between democracy satisfaction and interest in election campaigns $(F=380,22 ; d f=2 ; p<.001)$. The predictive value of democracy satisfaction via political interest on interest in election campaigns is $\% 23\left(R^{2}=0,22\right)$. Political interest shows a positive significant relationship with interest in election campaigns $(B=0,21 ; t=86,6 ; p<.001)$. Also democracy satisfaction shows a positive significant relationship with interest in election campaigns $(B=0,14 ; t=5,61 ; p<.001)$. It consequently can be stated, that compared to step $\mathrm{C}$, where the relationship between the independent variable democracy satisfaction and the dependent variable interest in election campaigns was tested, and political interest has a mediating effect. Political interest seems to be taking over a part of the effect of democracy satisfaction on interest in election campaigns. Finally we can adopt $\mathrm{H} 4$ that expected the mediating effect of political interest on the relationship between democracy satisfaction and interest in election campaigns.

Table 1 Regression analysis of interest in election campaign

\begin{tabular}{llll}
\hline Constant & $\mathrm{B}$ & Beta & Sig \\
Democracy Satisfaction & .159 & & .000 \\
Political Interest & .114 & .230 & .000 \\
\hline $\mathrm{R}^{2}$ & .214 & .472 & .000 \\
\hline $\mathrm{N}$ & & & .227 \\
\hline$*=p<.001$ & & & .396 \\
\hline
\end{tabular}

\section{Discussion}

In this research the role of democracy satisfaction was tested on the interest in election campaigns change and the mediating role that political interest plays in this relation. With the use of an existing dataset and by conducting single and multiple regressions, the presented conceptual model (figure 1) seemed to be valid. Because two effects that were expected to be significant positive and the results show positive relationship between democracy satisfaction and interest in politics, and between political interest and interest in election campaigns, $\mathrm{H} 1$ and $\mathrm{H} 2$ can be adopted. The expected significant positive effect of $\mathrm{H} 3$ was adopted, as well H4 that expected the mediating effect. These results will be discussed:

- There was an expected positive effect of democracy satisfaction on interest in campaigns. Accordingly, interest in campaigns increases the more people is satisfied with democracy. This might be explained by saying that democracy is the core component of having secular states, and people attend rallies, public meetings and etc. when they are satisfied with the way that democracy works in European Union.

- The second hypothesis that expected a positive effect of political interest on interest in election campaigns, similar with our expectation results was positive. The more people interested with politics seem to feel, the more they are interested with the election campaigns. Referring back to the literature discussed in the introduction, this is something we could have expected.

- The expected mediating effect of political interest in the relationship between democracy satisfaction and interest in election campaigns is confirmed by the results. In order to have more people who are interested in election campaigns, they should be prevented from feeling not interested in polls.

\section{Limitations}

In this study an existing dataset of each European Union member states was used. However, data were analysed collectively without making distinction between different European Union member states. Future research may focus on whether the same variables will vary for each European Union member 
state and how the conceptual model may be influenced. In the conceptual model that was used in this research, only one independent variable and one mediating variable were used. In reality however, multiple variables influence each other. Possibly other variables are influencing the relationships and effects that were tested such as; 'governing styles, and demographic differences' and therefore a more elaborate research could give a deeper insight in the matter. It is also possible that the scale of variables in the questionnaire might have been measured by 7 point Likert scale. Arguably one would expect that democracy satisfaction would increase political interest and therefore a positive effect was expected.

\section{References}

Baron, R. M., \& Kenny, D. A. (1986). The moderator-mediator variable distinction in social psychological research: Conceptual, strategic, and statistical considerations. Journal of Personality and Social Psychology, 51, 1173-1182.

Blumler, J. G., \& Kavanagh, D. (1999). The third age of political communication: Influences and features. Political Communication, 16, 209-230. 7

Brants, K., \& van Praag, P. (2006). Signs of media logic. Half a century of political communication in the Netherlands. Javnost - The Public, 13(1), 25-40.

De Vreese, C.H. and Semetko, H.A. (2002) Cynical and Engaged: Strategic Campaign Coverage, Public Opinion, and Mobilization in a Referendum. Communication Research, 29(6): 615-641.

Hallin, D. C., \& Mancini, P. (2004). Comparing Media Systems. Three models of media and politics. Chapter 8 "The forces and limits of homogenization".

Schuck, A.R.T. and de Vreese C.H. (2009) Reversed Mobilization in Referendum Campaigns: How Positive News Framing Can Mobilize the Skeptics, International Journal of Press/Politics, 14(1): 4066.

Van Aelst, P., Brants, K., van Praag, P., de Vreese, C. H., Nuytemans, M., \& van Dalen, A. (2008). The fourth estate as superpower? An empirical study of perceptions of media power in Belgium and the Netherlands. Journalism studies 9(4): 494-511. 